\title{
LIGHT SENSITIVITY OF ROSIN PAPER-SIZING MATERIALS ${ }^{1}$
}

\author{
By Arthur E. Kimberly ${ }^{2}$ and J. F. G. Hicks ${ }^{2}$
}

\section{ABSTRACT}

The effect of light upon rosin, and compounds of rosin formed during the rosin sizing of paper has been studied, both in air and in an atmosphere of nitrogen, a relatively inert gas. The source of light used was an inclosed carbon arc. Commercial rosin and bleached rosin as well as resinates of sodium, aluminum, and iron, and rosin size contaminated with ferrous and ferric iron were exposed to the rays of the arc in quartz tubes. The fact that changes occur in an inert atmosphere, such as nitrogen, indicates that the presence of oxygen is not necessary to the chemical alteration of rosin when exposed to the action of light.

The more important conclusions of this investigation follow: Rosin, both bleached and unbleached, is sensitive to light, darkening under the action of the rays. Ferrous resinate, and rosin size contaminated with ferrous iron are also light sensitive probably because of the ease with which the ferrous iron is oxidized by light. Ferric resinate, aluminum resinate, and sodium resinate have no effect upon rosin size in so far as light sensitivity is concerned. The yellowing of paper with age may be explained in terms of the light sensitivity of rosin and of ferrous iron.

\section{CONTENTS}

I. Introduction

II. Experiments performed

1. Effect of light upon rosin

2. The effect of light upon resinates of sodium, aluminum, ferrous iron, and ferric iron

3. The effect of light upon rosin size contaminated with ferrous and ferric iron, singly and together.

III. Discussion of experimental results

1. Effect of light upon rosin

2. Effect of light upon resinates of sodium, aluminum, and iron

3. The effect of light upon rosin size contaminated with ferrous and ferric iron

IV. Summary

\section{INTRODUCTION}

Light, according to the literature, is an important factor in the deterioration of high-grade papers, as is most frequently noticed in libraries or similar depositories of records. The term "high grade" is used in this instance to distinguish papers containing no ground wood fibers from those containing ground wood fibers. The change in color occasioned by the action of light upon papers containing ground wood has been attributed ${ }^{3}$ to the oxidation of the lignins contained in such fibers. In order to ascertain the effect of light upon the ma-

1 This series of investigations is being made at the request of the American Library Association, and is financed by a grant from the Carnegie Institution. The experimental work is being performed at the National Bureau of Standards.

2 Research associate, National Research Council.

3 Klason, P.: Svensk Pappierstidning. See translation by C. F. Bandelin, Payer Trade J., $5 \%$, pp. 17, 46; 1913. Compare Cross, C. F., Roy. Soc. Arts J., 45, p. $681 ; 1897$. 
terials comprising the rosin sizing used in the manufacture of papers containing no ground wood, as distinguished from the effect of light upon the paper fibers themselves, ${ }^{4}$ this phase of an investigation of the impermanency of records was inaugurated.

Klemm ${ }^{5}$ indicated that the yellow discoloration in paper was due to what he called "rosin-iron soaps," and that the intensity of the discoloration was generally proportional to the quantity of iron present. Schwalbe 6 found that rosin itself was very sensitive to both light and air, and that a rosin-sized paper, upon exposure to direct sunlight, underwent a rapid loss of sizing. Schoeller ${ }^{7}$ indicated that all papers turned yellow to a greater or lesser extent, with passage of time, more especially those which had been sized with rosin. He further indicated that the darkening of rosin itself was due to polymerization or auto-oxidation, and that the discoloring of papers would be prevented by "bleaching" the rosins used in size making with an oxidizing agent. ${ }^{8}$ Zschokke, ${ }^{9}$ working independently of Schoeller, showed results which partially agreed with those of Schoeller, but asserted that the color changes in paper are due to the effects of heat and light. He further disagrees with Klemm ${ }^{10}$ as to the direct relation between degree of discoloration and iron content of paper. At about the same time, Klason ${ }^{11}$ showed that rosin rapidly takes up atmospheric oxygen in the presence of sunlight, and only very slowly, if at all, in the dark. Haas ${ }^{12}$ recommended the use of "alum free from iron," and of "bleached rosin" to prevent the deterioration of paper. Hitchins ${ }^{13}$ showed that all rosin-sized papers will yellow with passage of time, that mere traces of iron will influence the depth of color produced, and that the iron content of a rosin-sized paper is therefore a very important factor. In addition to this somewhat contradictory collection of data, one finds in the journals relating to the paper industry several articles which appear to be résumés, translations or rewritings of the work just cited. ${ }^{14} 151617$ It appears that but little attempt has been made to connect the various color changes of rosins just described with the actual discoloring of paper, ${ }^{18}$ or to correlate the discoloration of sizes and of paper. ${ }^{19}{ }^{20}$ One does not find any attempt to distinguish between the behavior of ferrous compounds, ferric compounds, or mixtures of the two, in connection with the term "iron" as related to the discolorations discussed.

Because of the indefinite state of the knowledge concerning the cause of the discoloration of rosins and rosin sizes, and the relation

\footnotetext{
- Trans. Inst. Rubber Ind., 5, p. 31; 1929; also Rubber Chem. and Tech., 3, pp. 1, 57; 1930 . See also References 1,3 , and 4 .

\& Klemm Papier, Ztg. Jahrg. 27, 1902, pp, 961-963.

6 Schwalbe Wochbl, Papierfabr., 38, pp. 1303-1306; 1907.

7 Schoeller Wochbl, Papierfabr., 43, p. 3222 et seq.; 1912 (serial).

8 Schoeller's German Patent, Bleaching of Rosin, No. 257158; 1912.

Zschokke Wochbl, Papierfabr., 44, p. 2976 et seq.; 1913 (serial).

10 See footnoto 5 .

il See translation by O. E. Bandelin, Paper Trade J., 57, pp. 17, 46; 1913. Compare also Briggs, Chem-

ical World 2, p. 119; 1913.

${ }_{13}$ Haas, B., Papierfabrikant, 12, p. 891 et seq.; 1914 (serial).

${ }^{13}$ Hitchins, A. L., "Paper" pp. 11-15, July 24, 1918.

14 P'ulp and Paper Magazine of Canada, 11, p. 686; 1913.

is Paper Trade J., 58, pp. 18, 38; $A$ pril 30, 1914.

16 Papermakers' Monthly J., 56, p. 40; 1918; also "Paper," 22, pp. 1, 11; 1918.

17 " "Paler" 30, pp. 7, 70-72; 1922; also Paper Trade J., 74, pp. 15, 313-315; 1922

18 "Paper," 30, pp. 7, 70-72; 1922; also, Paper Trado J., 74, pp. 15, 313-315; 1922.

10 Paper Trade J., 76, pp. 11, 50-52; 1922.

${ }^{20}$ Cieseboff, L. I., "La Papeterio"; March 23, 1023; also "Paper," 31, pp. 26, 143; 1923.
} 
between these discolorations and the discoloration of papers, it was thought advisable to study the behavior of rosin, bleached ${ }^{21}$ and unbleached, when exposed to the action of light, the samples of rosins to be placed in separate atmospheres, both chemically inert and chemically active with respect to the rosins placed in them. Since the rosins, sizes, chemicals, and papers were and always have been made and stored in air, these artificial atmospheres must represent conditions based upon that fact. The ordinary components of the atmosphere were, therefore, used singly and together.

For the same reason, it was thought advisable to study the behavior of rosin and rosin sizes, when intimately mixed with small quantities of different types of "iron compounds" 22 and placed under the influence of light. The usual commercial process of sizing paper with rosin is, briefly, as follows: The rosin is heated with a solution of "soda ash" (commercial sodium carbonate) to such a degree as to hold the remaining free rosin in colloidal suspension. The size and the pulp are well mixed in the beating machine, and a calculated amount of so-called "paper makers' alum" (aluminum sulphate) is added. This precipitates the rosin upon the paper fibers, which are then run through the machine and formed into sheets. There are many modifications of this general procedure, but, for the most part, they are minor deviations. By reason of the method of manufacture, rosin sizes, as used in a paper mill, contain the resinates of sodium, aluminum, ferrous and ferric iron, in addition to colloidal rosin. The precipitating agent for these rosin sizes, aluminum sulphate, nearly always contains traces of both ferrous and ferric iron, detectable by the ordinary reagents; hence, the presence, in such a size, of ferrous and ferric resinates, is readily accounted for. These facts made it necessary to add known small quantities of "iron compounds" to "iron free" sizes ${ }^{23}$ and study the behavior of these under the influence of light. The addition of traces of solutions of iron salts to the liquid "size milk" makes possible a very intimate mixture, similar to that existing on the surface of a commercial rosin sized paper.

The effect of light upon rosin, alone and in combination with other materials, was studied. A study of bleached rosin was included in the program, since it has been claimed ${ }^{24}$ that bleached rosin does not darken upon exposure to light. The source of light in these experiments was a carbon-arc lamp, operated with a direct current of 13 amperes at 220 volts, at a distance of $10 \mathrm{~cm}$ from the samples, and inclosed in a globe of special glass. These special glass globes are described by their manufacturers as deteriorating at the end of 100 light-hours' service; for this reason they were replaced at the ind of each total 75 light-hours' service, as an additional precaution.

21 Although the use of "bleached" rosin has been strongly advocated by some of the German investiators, it is not known that their recommendations were ever put into practice. So far as is known, no "bleached" rosin has been used in the United States.

${ }_{22}$ To avoid needless repetition "iron compounds" as used in this discussion will be taken to mean "ferous and ferric compounds singly and together." Details of making such "iron compounds" will be given inder the head of "Experiments Performed."

${ }^{23}$ The term "iron free" here and elsewhere in this publication means "tested for both Fet+ and Fet+

rith negative results." Further details under the head of "Experiments Performed."

24 Schoeller, V., see footnotes 7 and 8, p. 820; Haas, B., Papierfabrikant, 1※, pp. 891 and $919 ; 1914$. 
The spectral distribution of radiation from such a glass-inclosed arc as this, as compared with sunlight, is as follows: ${ }^{25}$

\begin{tabular}{|c|c|c|}
\hline \multirow{2}{*}{ Spectral range in $\mu \mu$} & \multicolumn{2}{|c|}{$\begin{array}{l}\text { Percentage of total } \\
\text { radiation }\end{array}$} \\
\hline & Arc & Sun \\
\hline $\begin{array}{l}170 \text { to } 320 \\
320 \text { to } 3600 \\
360 \text { to } 480 \\
480 \text { to } 600 \\
1,400 \text { to } 4,200 \\
4,200 \text { to } 12,000\end{array}$ & $\begin{array}{r}0.0 \\
2.0 \\
18.5 \\
9.3 \\
2.1 \\
31.6\end{array}$ & $\begin{array}{r}2.0 \\
2.8 \\
12.6 \\
21.9 \\
21.4 \\
.4\end{array}$ \\
\hline
\end{tabular}

\section{EXPERIMENTS PERFORIMED}

\section{EFFECT OF LIGHT UPON ROSIN}

Four varieties of rosin were used in this phase of the work:

(a) Unbleached rosin, grade $\mathrm{F}$, such as is commonly used for sizing paper.

(b) Unbleached rosin, grade C, lighter in color than grade $\mathrm{F}$. Used in papers when a lighter color is particularly important.

(c) Rosin, grade F, bleached as follows: The rosin was melted on the steam bath, and chlorine gas passed through the melt until the color of the rosin no longer lightened on continued passage of chlorine. The resulting mass was then converted into sodium resinate by the addition of an excess of sodium-hydroxide solution, and the mixture heated on the steam bath until a clear liquid resulted. This sodiumresinate solution was then acidified by adding an excess of strong hydrochloric acid, which precipitated free rosin therefrom. This free rosin was filtered off, washed twice with distilled water, and dried in contact with air. This is Schoeller's method.

(d) Rosin, grade F, bleached as follows: The rosin was mixed with a slight excess of sodium carbonate solution, and the mixture heated on the steam bath until a clear liquid was obtained. Chlorine gas was then passed through this liquid until no further lightening of color was observed upon continued passage of the gas. Free rosin was precipitated from this liquid by adding an excess of strong hydrochloric acid, and the free rosin was then filtered off, washed twice with distilled water, and dried in contact with air.

Specimens of each of these rosins were then placed in quartz tubes, one specimen of rosin in each quartz tube, and the tubes connected with gas trains in such a manner that each separate sample of each variety of rosin was surrounded by one of the following gases: ${ }^{26}$

Purified nitrogen, from which the admixed oxygen and carbon dioxide had been removed by passing the gas through a train consisting of gas wash bottles containing a mixed solution of potassium pyrogallate and potassium hydroxide.

Purified oxygen, from which the admixed carbon dioxide had been removed by pasing the gas through a train of gas wash bottles containing potassium hydrcxide solution.

Purified carbon dioxide, from which the admixed oxygen had been removed by passing the gas through a train of wash bottles containing cuprous chloride $(\mathrm{CuCl})$ dissolved in hydrochloric acid, to which solution metallic copper had been added. The acid fumes were caught in a saturated solution of sodium bicarbonate, thereby preventing removal of carbon dioxide by the train itself.

25 Measurements by W. W. Cablentz, Bureau of Standards.

${ }_{26}$ The composition of these artificial atmospheres is based on the composition of the air, as has been pre* viously mentioned, with reasons for choice, in the Introduction. 
Purified air, which had been washed free from dust by means of a train of bottles containing water, after which the excess moisture was removed by means of a train of calcium chloride towers.

Air with carbon dioxide removed. This was brought about by passing the air through a train of wash bottles containing a solution of potassium hydroxide.

Before coming into contact with the rosin samples, each gas was dried to such a degree that it contained 0.14 to $0.36 \mathrm{mg}$ of residual water-vapor per liter at $25^{\circ} \mathrm{C}$.

Duplicate samples of these rosins were sealed in glass tubes, the air in which had been displaced by each of the purified gases just described. These sealed tubes were preserved in total darkness. In this way there was always on hand a set of reference samples representing the color of the rosin in the dark at the start of the experiment, one sample for every gas used.

The test samples of rosin, bleached and unbleached, each in its separate quartz tube and each surrounded by its own purified and uniformly dried gas-nitrogen, oxygen, carbon dioxide, air, and air less carbon dioxide, as the case might be-were then exposed to the action of the adopted source of light (q. v.) for a total period of 288 hours. At the end of that elapsed time the test samples were removed from the source of light and compared with the reference samples. Results are collected and shown in Table 1.

TABLE 1.-Effect of light upon rosin 12

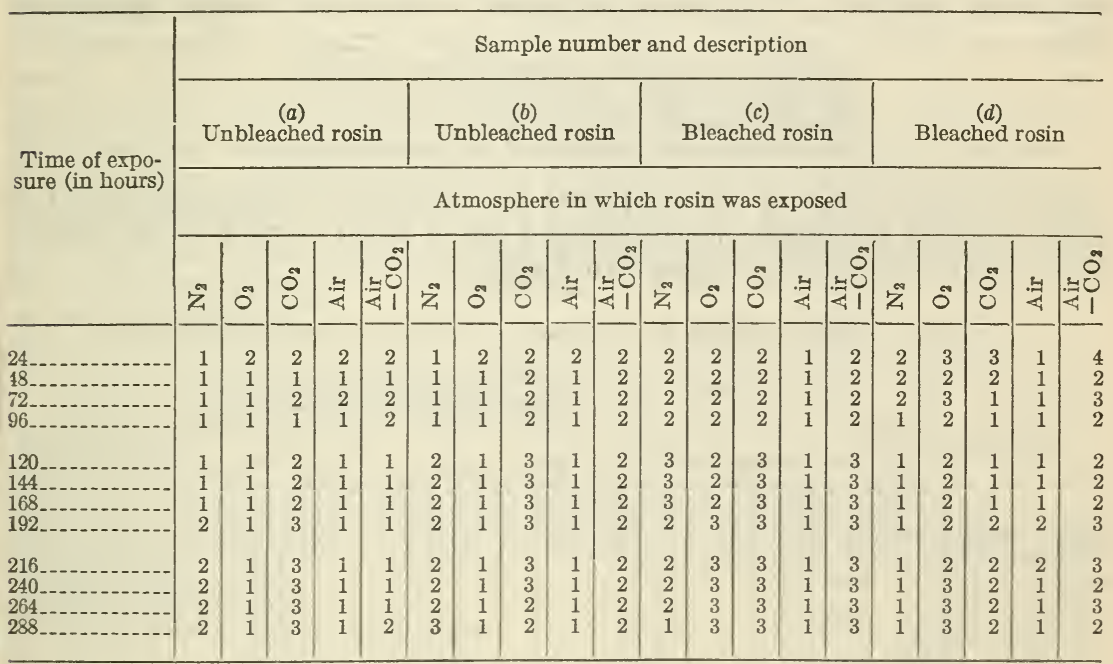

1 Color is expressed by a comparative numerical scale: 1 , darkest, to 5 , lightest. Before exposure to light, the original sample was lighter in color than " 5 ."

2 At the end of each 24-hour period each set of tubes, $(a),(b),(c)$, and $(d)$, were compared with the corresponding original sample and with each other. The numbers in this table represent the results of these comparisons, and are not comparable to preceding or succeeding observations.

\section{THE EFFECT OF LIGHT UPON RESINATES OF SODIUM, ALUMINUM, AND IRON}

The compounds of rosin which are usually met with in papermaking processes are the "resinates" of sodium, aluminum, ferrous and ferric iron: In order to protect the compounds used in these experiments from the action of light, the whole process of preparing these resinates was conducted in a photographic dark room. 
These resinates of aluminum and of ferrous and ferric iron were made by transposing sodium resinate ${ }^{27}$ with the sulphates of the metals just mentioned. Aqueous solutions, using triple-distilled water, were used in these reactions. The method of operation was as follows: The sodium resinate and one of the three solutions of metallic sulphates were each placed in separate $250 \mathrm{ml}$ Erlenmeyer flasks, previously swept free of air by a stream of purified nitrogen. The two flasks were connected with each other in the same manner as a train of gas wash bottles, so that the liquid contents of each could be agitated by bubbling, transferred by blowing the contents of one flask into the other, and mixed by bubbling. The gas used for these purposes was the purified nitrogen just described. After blowing this stream of purified nitrogen through the system for five minutes, the metallic sulphate solution was blown over into the sodium resinate solution, and mixed with it by bubbling. The precipitated resinates were washed in this manner with distilled water, filtered by suction, in an atmosphere of purified nitrogen gas, and dried in a desiccator filled with purified nitrogen. All these operations were conducted in a photographic dark room. Samples of these resinates were sealed in pyrex glass tubes, which contained an atmosphere of purified nitrogen, and stored in the dark for use. Two tubes of each resinate were prepared. One set of these tubes was placed in the light of the carbon arc lamp, while the other set was preserved in total darkness as a reference sample. The colors of these compounds before exposure were:

Aluminum resinate: White to pale yellow.

Sodium resinate: White to pale yellow.

Ferrous resinate: Light tan.

Ferric resinate: Yellow-brown to red brown.

Those resinates which were exposed to the adopted source of light for experimental purposes, were exposed for a total period of 25 hours. The results obtained are shown in Table 2.

$\mathrm{T}_{\mathrm{ABLE}}$ 2.-Effect of light on resinates of sodium, aluminum, and iron

\begin{tabular}{|c|c|c|c|c|c|c|c|}
\hline \multirow{2}{*}{ Substance exposed } & \multicolumn{7}{|c|}{ Time of exposure (in hours) } \\
\hline & 1 & 2 & 7 & 9 & 14 & 19 & 25 \\
\hline $\begin{array}{l}\text { Sodium resinate from un- } \\
\text { bleached rosin. }\end{array}$ & $\left({ }^{(}\right) \ldots$ & (a) - - & $(a)$ & $(a) \ldots$ & $\left({ }^{a}\right)$ & (a) & $\left({ }^{a}\right)$ \\
\hline $\begin{array}{l}\text { Sodium resinate from } \\
\text { bleached rosin }\end{array}$ & $(a)$ & & & & (a) & $\left({ }^{(}\right)$ & $\left({ }^{a}\right)$ \\
\hline $\begin{array}{l}\text { Aluminum resinate from } \\
\text { unbleached rosin. }\end{array}$ & & & & (a) & $\left({ }^{a}\right)$ & (a) & $(a)$ \\
\hline $\begin{array}{l}\text { Aluminum resinate from } \\
\text { bleached rosin. }\end{array}$ & (a). & $\left({ }^{a}\right)$ - & (a). & (a) $\ldots$ & $\left({ }^{(}\right)$ & (a) & $(a)$ \\
\hline $\begin{array}{l}\text { Ferrous resinate from un- } \\
\text { bleached rosin. }\end{array}$ & No change. - & Slight darkening - & $\begin{array}{l}\text { Increased dark- } \\
\text { ening. }\end{array}$ & $\begin{array}{l}\text { Distinctly } \\
\text { darker. }\end{array}$ & (b) & (b) & (b) \\
\hline $\begin{array}{l}\text { Ferrous resinate from } \\
\text { bleached rosin. }\end{array}$ & ...... do & $\begin{array}{l}\text { Noticeable dark- } \\
\text { ening. }\end{array}$ & Very dark color: & & ( & (b) & (b) \\
\hline $\begin{array}{l}\text { Ferric resinate from un- } \\
\text { bleached rosin. }\end{array}$ & $(a)$ & (a) & & & $\left({ }^{(a)}\right.$ & (a) & $(a)$ \\
\hline $\begin{array}{l}\text { Ferric resinate from } \\
\text { bleached rosin. }\end{array}$ & $\left({ }^{a}\right)$ & (a) & $\left({ }^{a}\right) \ldots$ & $\left({ }^{a}\right)$ & $(a)$ & (a) & (a) \\
\hline
\end{tabular}


With the exception of the rosins, the chemicals used-sodium hydroxide, sodium carbonate, and the sulphates of aluminum, ferric and ferrous iron-were of the "C. P." variety. Since iron salts were to be added to various compounds which contained no iron during the course of the experimental work, the first three of these chemicals, as well as the rosins and solvent acids, were tested for and found free from iron. ${ }^{28}$

The water used in making the solutions used in this series of expcriments was triple distilled water, which had been boiled for six hours, during which time a stream of purified nitrogen was bubbled through it, for the purpose of sweeping out dissolved oxygen, since ferrous iron was to be put into solution. This water was kept in stoppered flasks until ready for use.

\section{THE EFFECT OF LIGHT UPON ROSIN SIZE CONTAMINATED WITH FERROUS AND FERRIC IRON ${ }^{29}$}

Since Schoeller ${ }^{30}$ and others ${ }^{31}$ have claimed that the rosin size used in making papers is responsible for the discoloration of papers, and even their subsequent deterioration, and since it has been claimed ${ }^{32}$ that small quantities of iron hastened the discoloration and deterioration of both size and paper, it was thought advisable to study the behavior of rosin sizes contaminated with known small quantities of ferrous and ferric iron. The "size milk" used was obtained from the Bureau of Standards paper mill, and contained 30 per cent of "free" (colloidal) rosin. Samples of this size milk were contaminated with solutions of ferrous and ferric iron in concentrations ranging from 1 part of iron in 100,000 to a concentration of 1 part of iron in $1,000,000,000$. These contaminated samples of "size milk" were prepared in duplicate, one set being sealed in quartz tubes in air for exposure to the action of light, and the other set sealed in hard glass tubes in air and preserved in total darkness, as reference samples. The results of a run of 192 light hours are shown in Table 3.

\footnotetext{
${ }^{28}$ For Fe++: Potassium ferricyanide, in presence of $\mathrm{HCl}$. $\}$ (See Koningh, Z. Angew. Chem., 1898) p. 463.

For Fe++t: Potassium thiocyanate. (See Wagner, Zeit. Anal. Chem., 20, p. 350; 1881; also Natanson, Ann 130, p. $246 ; 1864$.

By these means a detection of 1 part of iron per 500,000 to $1,600,000$ parts of water is claimed by the above authors. The chemicals were tested in $10 \mathrm{~g}$ samples, as above, with negative results; the rosins, after decomposition of $40 \mathrm{~g}$ samples by hot concentrated sulphuric acid, also yielded negative results.

29 In order to avoid ambiguity of meaning and awkwardness of expression, "ferrous and ferric iron" as used in this discussion means "taken singly and together," and "together" means "equimolar concentrations of each."

${ }^{30}$ See footnote 7, p. 820 .

31 See footnote 3, p. 819 , and 13 , p. 820

32 See footnote 3, p. 819 , and 5 and 13 , p. 820.
} 
TABLE 3.-Effect of light on rosin size contaminated with ferrous and ferric iron ${ }^{1}$

\begin{tabular}{|c|c|c|c|c|c|c|c|c|c|}
\hline \multirow{2}{*}{ Contaminating agent } & \multirow{2}{*}{$\begin{array}{c}\text { Concentration of } \\
\text { contaminating agent }\end{array}$} & \multicolumn{8}{|c|}{ Time of exposure (in hours) ${ }^{1}$} \\
\hline & & 24 & 48 & 72 & 96 & 120 & 144 & 168 & 192 \\
\hline Ferrous iron.... & $\left\{\begin{array}{l}1: 100,000 \\
1: 1,000,000 \\
1: 10,000,000 \\
1: 100,000,000\end{array}\right.$ & $\begin{array}{l}2 \\
1 \\
3 \\
4 \\
5\end{array}$ & $\begin{array}{l}2 \\
1 \\
3 \\
4 \\
5\end{array}$ & $\begin{array}{l}2 \\
1 \\
3 \\
4 \\
5\end{array}$ & $\begin{array}{l}2 \\
1 \\
3 \\
4 \\
5\end{array}$ & $\begin{array}{l}2 \\
1 \\
3 \\
4 \\
5\end{array}$ & $\begin{array}{l}2 \\
1 \\
3 \\
4 \\
5\end{array}$ & $\begin{array}{l}2 \\
1 \\
3 \\
4 \\
5\end{array}$ & $\begin{array}{l}2 \\
1 \\
3 \\
4 \\
5\end{array}$ \\
\hline Ferric iron.... & $\left\{\begin{array}{l}1: 100,000 \\
1: 1,000,000 \\
1: 10,000,000 \\
1: 100,000,000 \\
1: 1,000,000,000\end{array}\right.$ & $\begin{array}{l}(2) \\
(2) \\
(2) \\
(2) \\
(2)\end{array}$ & $\begin{array}{l}(2) \\
(2) \\
(2) \\
(2) \\
(2)\end{array}$ & $\begin{array}{l}(2) \\
(2) \\
(2) \\
(2) \\
(2)\end{array}$ & $\begin{array}{l}(2) \\
(3) \\
(2) \\
(2) \\
(2)\end{array}$ & $\begin{array}{l}(2) \\
(2) \\
(2) \\
(2) \\
(2)\end{array}$ & $\begin{array}{l}(2) \\
(2) \\
(3) \\
(2) \\
(2)\end{array}$ & $\begin{array}{l}(2) \\
(2) \\
(2) \\
(2) \\
(2)\end{array}$ & $\begin{array}{l}(2) \\
(2) \\
(2) \\
(2) \\
(2)\end{array}$ \\
\hline Ferrous and ferric iron ${ }^{3}$.. & $\left\{\begin{array}{l}1: 100,000 \\
1: 1,000,000 \\
1: 10,000,000 \\
1: 100,000,000 \\
1: 1,000,000,000\end{array}\right.$ & $\begin{array}{l}3 \\
2 \\
(2) \\
(2) \\
(2)\end{array}$ & $\begin{array}{l}3 \\
2 \\
(2) \\
(2) \\
(2)\end{array}$ & $\begin{array}{l}3 \\
2 \\
(2) \\
(2) \\
(2)\end{array}$ & $\begin{array}{r}3 \\
2 \\
(2) \\
(2) \\
(3)\end{array}$ & $\begin{array}{l}3 \\
2 \\
(2) \\
(2) \\
(3)\end{array}$ & $\begin{array}{l}3 \\
2 \\
(2) \\
(2) \\
(2)\end{array}$ & $\begin{array}{l}3 \\
2 \\
(2) \\
(2) \\
(2)\end{array}$ & $\begin{array}{l}3 \\
\text { (2) } \\
\text { (2) } \\
\text { (2) }\end{array}$ \\
\hline
\end{tabular}

1 At the end of each 24-hour period each set of tubes was compared with the corresponding original sample and with each other. The numbers in this table represent the results of these comparisons, and are not comparable to preceding or succeeding observations.

2 No apparent color change.

3 In equimolar concentrations.

Note.-Color is expressed by a comparative numerical scale:, 1 (darkest) to 5 (lightest). Before exposure to light, the original sample was lighter in color than "5."

\section{DISCUSSION OF EXPERIMENTAL RESULTS}

\section{EFFECT OF LIGHT UPON ROSIN}

All of the samples of rosin which were exposed to the action of the adopted source of light darkened in color to a considerable degree, regardless of the artificial gas atmosphere used. However, the bleached and unbleached specimens differed as to comparative behavior with respect to light in every artificial atmosphere used, with the exception of air and, in a single instance, carbon dioxide. In the case of the unbleached samples, maximum darkening occurred in those tubes which contained oxygen or air. Some color changes were observed in the absence of oxygen, indicating that the unbleached rosin can be affected by light alone. The increased effect in the presence of oxygen would indicate a photochemical oxidation. On the other hand, the bleached rosins darkened most in those tubes which contained nitrogen or air, which would tend to show that oxygen is not essential to a considerable change in bleached rosins upon exposure to light. Abietic acid, found in ordinary rosins, contains one double carbon bond, and, therefore, may be expected to add two atoms of chlorine when subjected to bleaching as described. Such chlorinated compounds are, in general, unstable to light. ${ }^{33}$ These observations are at variance with the recommendations of Schoeller ${ }^{34}$ and Haas ${ }^{35}$ as to the use of "bleached" rosin for the manufacture of paper size. The fact that rosin, bleached as recommended, was observed to darken in color under the influence of light eliminates it from consideration as a substitute for unbleached rosin on the basis of comparative light sensitivity.

\footnotetext{
93 Plotnikow, Lehrbuch der Photochemie, p. 547; 1919.

34 See footnotes 7 and $x$, p. 820 .

as Seo footnote 12 , p. 820 .
} 


\section{EFFECT OF LIGHT UPON RESINATES OF SODIUM, ALUMINUM, AND IRON}

Ferrous resinate was the only one of these compounds which yielded a visible color change upon an exposure of 25 hours. Regardless of whether bleached or unbleached rosin was used, a distinct change in color was observed after an exposure of two hours. This effect is probably due to a photochemical change in valence of ferrous to ferric iron.

\section{EFFECT OF LIGHT UPON ROSIN SIZE, CONTAMINATED WITH FERROUS AND FERRIC IRON, SINGLY AND TOGETHER ${ }^{36}$}

The samples of "size milk" containing ferrous iron alone all darkened in color upon exposure to light, exhibiting a maximum darkening in the samples containing 1 part of ferrous iron per 1,000,000 parts of "size milk." Apparently this is a critical concentration. None of the samples to which ferric iron alone had been added exhibited any change in color. The evidence indicates that the ferrous iron catalyzes the action of light upon the rosin size examined. Catalysis of photochemical reactions by traces of ferrous iron is a well-known phenomenon. ${ }^{37}$ The color of this intimate mixture of ferrous resinate and rosin after exposure to light is much darker than is the color of rosin similarly exposed.

\section{SUMMARY}

As a result of this study of the effect of light upon rosin and rosin size, the following conclusions may be drawn:

1. Rosin is light sensitive, and darkens in color even in an atmosphere of an inert gas.

2. Both bleached and unbleached rosin show approximately the same degree of change in color.

3 . Ferrous resinate is light sensitive, and the color change it undergoes upon exposure to light is probably due to photochemical change in valence of ferrous iron to ferric iron. Ferric resinate, aluminum resinate, and sodium resinate are not light sensitive.

4. An intimate mixture of ferrous resinate and rosin, as found in rosin size contaminated with quantities of ferrous iron smaller than those usually found in industrial waters, is light sensitive to a greater degree than rosin alone. The evidence indicates that the ferrous iron catalyzes the action of light upon the rosin size examined.

5. Since rosin-sized paper contains rosin, ferrous resinate, and rosin size contaminated with ferrous iron, and since these substances have been shown to be sensitive to light, some relationship must exist between these facts and the discoloration ("yellowing") of papers upon exposure to light.

6. This article reports the first of a series of investigations as to the deteriorative agencies and their effects upon the components of paper.

Washington, February 10, 1931.

36 See footnote 22, p. 821.

37 Plotnikow, Lehrbach der Photochemie, p. 320; 1919. $49527^{\circ}-31-5$ 